\title{
A prototype of 3D-printed permanent magnet generator for low power applications
}

\author{
Chaiyong Soemphol, Adisorn Nuan-on, Peeradapath Parametpisit \\ Research Unit for Computational Electromagnetics and Optical Systems (CEMOS), Department of Electrical Engineering, \\ Faculty of Engineering, Mahasarakham University, Kantarawichai, Thailand
}

\begin{tabular}{l} 
Article Info \\
\hline Article history: \\
Received Jul 30, 2021 \\
Revised Nov 16, 2021 \\
Accepted Nov 26, 2021 \\
\hline
\end{tabular}

Keywords:

3D-printed

Electrical machine design

Low-power system

Machine assembly

Permanent magnet generator

\begin{abstract}
Recently, there has been a growing interest in the field of using 3D-printing technology for electrical machine manufacturing. However, almost research works have been done majorly on the 3D-printing technology of individual working parts for various electrical machines. This research presents a study of design, fabrication and testing of the protopype of permanent magnet generator using 3D-printing technology. The major parts of proposed generator are fabricated though 3D-printed materials. The stator winding of designed generator consists of 12 slots. The stator coil is designed to have 250 turns per slot and 12 pieces of neodymium magnets are used in to generate magnetic field in the rotor core. The prototype generator is tested under different condition; no-load and loaded-test. The experimental have been shown that in the no-load condition, this generator is able to generate output voltage of 3.3-64.5 V, when rotated at speed of 100-2,500 rpm. In the loaded-test, the output voltage and output current are also generated. Furthermore, it can be seen that a proposed generator can generate the output power of 4,245.28 $\mathrm{mW}$, when rotated at speed of 2,500 rpm.
\end{abstract}

This is an open access article under the CC BY-SA license.

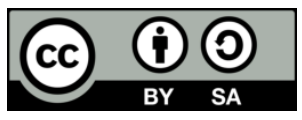

\section{Corresponding Author:}

Chaiyong Soemphol

Research Unit for Computational Electromagnetics and Optical Systems (CEMOS)

Department of Electrical Engineering, Faculty of Engineering, Mahasarakham University

Kantarawichai, Maha Sarakham, 44150, Thailand

Email: chaiyong.s@msu.ac.th

\section{INTRODUCTION}

Due to the growing interest in electrical machine are adopted in more applications, the modern electrical machine design is facing challenges in term of requiring more extraordinary performance parameters than conventional machine such as high specific power and harsh environments. These reasons are the motivation for researcher to explore the impact of advanced materials and fabrication technique on the performance of electrical machines. Additive manufacturing also known as 3D-printing technology is used for processes where the manufacturing is done in layers, rendered from the digital model of a specific item or assembly [1]. This technology has been undergoing dynamic development in recent year. It has been found that using of 3D-printing technogoly can open new challenging for design solutions that impossible to use a conventional techniqes for machine fabrication [2]. Furthermore, it has been reported that the lastest development of this technology has been recognized that it can offerer virtually unlimited potential for various applications such as biomedical applications [3], [4], RF/microwave components [5]-[8], antenna [9], [10], electromagnetic shielding [11], aerial vehicle wing structures [12], as well as electrical machines [13]-[21]. The studies have been reported that 3D-printing has a lot to offer in almost aspect of fabrication progress for electrical machines for example reduction in time, weight and cost of production, enablement of complex/application-specific design realizations as well as the opportunation of integrated functionalities 
within individual assemblies [1]. In recently, research work of 3D-printing has been done majorly on individual working parts for various electrical machines for instance coils or windings [13], [14], permanent magnets (PM) [15]-[18], and stator/rotor packs [19], [20]. Furthermore, the research has been presented a using of 3D-printed to fabricate prototype axial flux switched reluctance electrical machine [21].

Permanent magnet generator is one of electrical machine type that commonly used in a renewable power generation system [22]-[25]. There is no need of a separate dc source for the excitation for this generator type. It can generate the magnetic field and directly generate an output votage when the rotor is rotated. Permanent magnet generator offers the many advantages over traditional alternating current (AC) alternator systems. One of the main advantages of permanent magnet generator is physical benefits. This machine can design to reduce in weight and length, as well as it is easy to couple with other electronic device. Due to the promising aspect of what 3D-printing technology has to offer, it has also attracted interest from the permanent magnet generator construction. Several designs of permanent magnet generators using 3Dprinting technology have been proposed such as triboelectric generator [26], [27], electrostatic generator [28] as well as permanent magnet generator [29]-[31]. However, almost research works about 3D-printed generator are currently on initial stages of development. A completed 3D-printed permanent magnet generator for large-scale production and industrial applications are a work that have not been accomplished.

In this work, we have been investigated the possibilities of implementing 3D-printed materials for using as permanent magnet generator components. Following sections will explain the design of 3D-printed generator, fabrication, and the last one is a testing of the prototype 3D-printed generator. The results from noload and nominal load operation are presented. Such results demonstrate the pracicability of proposed generator for the low power system.

\section{RESEARCH METHOD}

Generally, the excitation of permanent magnet generator is provided with the permanent magnet instead of the external excitation source. The working of the permanent magnet generator depends on the field produced by the permanent magnet attached at the rotor of the generator for the conversion of mechanical energy into electrical energy. In this work, the prototype of generator consists of geometry design of stator, rotor, coil, magnet, both air gap of stator and rotor. This research is initiated by designing the stator winding. The design of stator winding is influenced by the number of slots in the stator, number of pole, the width of slot as well as the type and cross sectional area of wire [32]. While the rotor core design depends on the number of magnets, the dimension and the density of magnetic flux that can be found in the market and the installation of magnets in the rotor core [33]. In this work, the 3D-printed generator in [29] is developed to has better performance. The main criteria for parameter selections are the cost and the generator performance. The initialized geometry design of permanent magnet generator can be seen in Table 1 .

\begin{tabular}{cc} 
Table 1. Dimensions of proposed generator \\
\cline { 2 - 2 } \multicolumn{1}{c}{ Parameters } & Value \\
\hline Pole numbers & 12 \\
Stator slot for winding & 12 \\
Roter diameter & $85 \mathrm{~mm}$ \\
Lengnt of stator stack & $150 \mathrm{~mm}$ \\
Stator inner diameter & $90 \mathrm{~mm}$ \\
Stator outer diameter & $130 \mathrm{~mm}$ \\
Air gab length & $2.5 \mathrm{~mm}$ \\
Magnet dimenion & $50 \times 15 \times 5 \mathrm{~mm}$ \\
\hline
\end{tabular}

The stator winding of proposed generator is designed to has 250 turns on each slot. An AG27 copper conductor wire is used for stator winding. For winding the coils, it is essential to carefully count the turns, to make sure one turn of copper conductor is set next to the other and to tense the conductor enough, as this results in less gaps in between the turns of copper conductors and thus more successful coils [25]. The rotor has a permanent magnet that connected to the bearing rotating on the shaft. The shaft diameter of generator is designed to guarantee the safe transfer of the mechanical power from the driver unit to the generator. Highstrength 12 pieces of neodymium magnets are used to produce the external magnetic fields in a rotor. The reason to use neodymium magnets for this generator because these materials are reasonably easy to find and there are stronger magnets for less volume when compared to other magnets [29].

In this work, the Meta Bolt V2 3D-printer is used to construct the prototype generator. Polylactic acid (PLA) is used as 3D printing filament. The reason to use PLA filament because it is easy to use and is made from renewable resources and thus, biodegradable. The printer is controlled via Repetier Software. The 
temperature of the nozzle and heating bed are set to 220 and $60{ }^{\circ} \mathrm{C}$, respectively. Normal PLA filament with $1.75 \mathrm{~mm}$ of diameter is used to construct stator and rotor. The layer height or layer resolution and printing speed are chosen to be $0.2 \mu \mathrm{m}$ and $50 \mathrm{~mm} / \mathrm{s}$ respectively. In addition, thin supports with a height of $0.2 \mathrm{~mm}$ are included via 3D printing in order to mount the generator. These supports are thin enough to have a negligible effect on the generator. The stator, rotor and completed permanent magnet generator using 3Dprinter are presented in Figures 1(a)-(c).

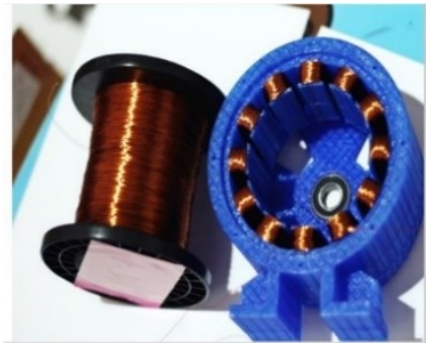

(a)

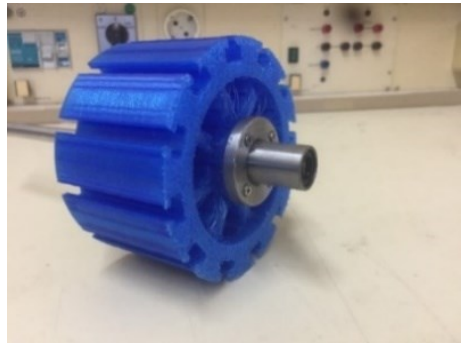

(b)

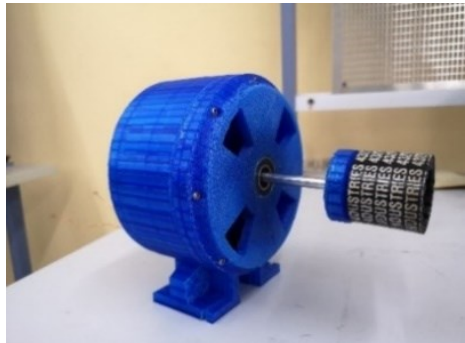

(c)

Figure 1. Fabricated of 3D-printed permanent magnet generator: (a) stator with copper winding, (b) rotor core with 12 poles permanent magnet, and (c) completely assembled generator

\section{EXPERIMENTAL SETUP}

The prototype of a 3D-printed permanent magnet generator is tested in the laboratory. The experimental setup is shown in Figure 2. The generator is rotated by using a direct current (DC) motor equipped with servo brake and speed controller. The experiments are conducted in two conditons. First, the generator is running without any load for observing an amout of voltage that proposed generator can be produced. For the second condition, the generator is running with a load of $7 \mathrm{~W}$ bulb. The current that produced from the second experiment can be conducted by Ampere meter while voltage of all experiments can be monitored by Voltmeter. The prototype of a 3D-printed permanent magnet generator is tested with rotational speed from $100-2,500 \mathrm{rpm}$.

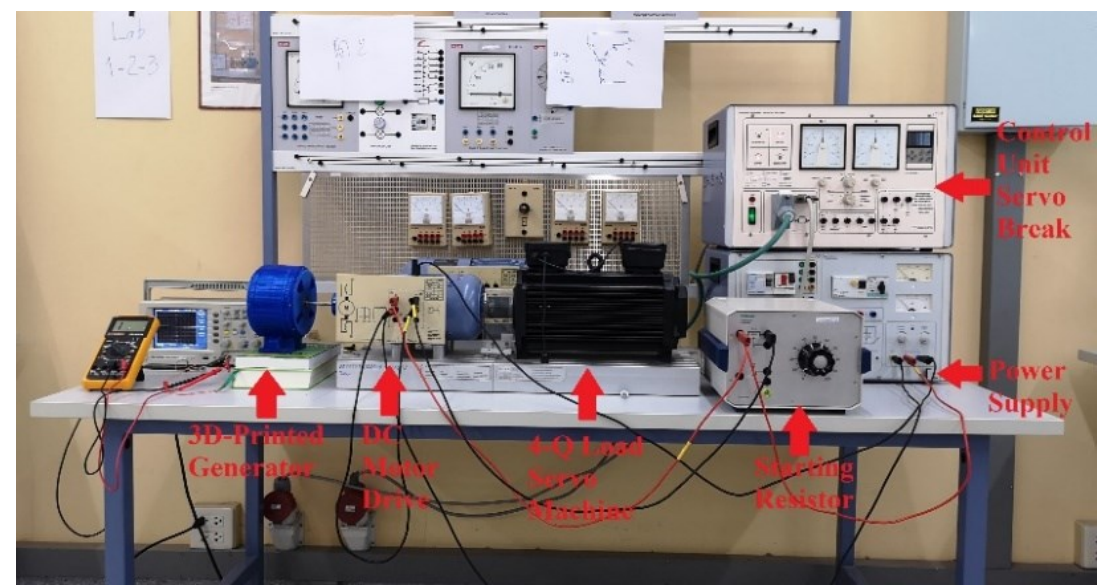

Figure 2. Experimental setup of testing of the 3D-printed permanent magnet generator

\section{RESULTS AND DISCUSSION}

\subsection{No-load test of 3D-printed permanent magnet generator}

The measurment results of voltage produced from the 3D-printed permanent magnet generator in no-load condition with different speed test are demonstrated in Table 2. It can be seen that when the generator is rotated at speed $100 \mathrm{rpm}$, a voltage of $3.3 \mathrm{~V}$ is generarated. When the rotation speed is increased to 2,500 rpm, output voltage of $64.5 \mathrm{~V}$ is generated. By varying the rotation speed ranging from 100 to 2,500 $\mathrm{rpm}$, the generated output voltage will be increased from 3.3 to $64.5 \mathrm{~V}$. From these experimental results it can 
be summarized that increasing the speed of generator will increase the generated voltage as shown the relationship between rotation speed and output voltage in Figure 3.

Table 2. The results of no-load test

\begin{tabular}{cc}
\hline Speed $(\mathrm{rpm})$ & Voltage $(\mathrm{V})$ \\
\hline 100 & 3.3 \\
200 & 5.7 \\
300 & 8.2 \\
400 & 11.2 \\
500 & 13.8 \\
600 & 16.4 \\
700 & 19.3 \\
800 & 21.8 \\
900 & 24.5 \\
1,000 & 27.1 \\
1,100 & 29.6 \\
1,200 & 32.5 \\
1,300 & 35.2 \\
1,400 & 37.7 \\
1,500 & 40.4 \\
1,600 & 41.4 \\
1,700 & 44.1 \\
1,800 & 46.5 \\
1,900 & 49.2 \\
2,000 & 51.7 \\
2,100 & 54.4 \\
2,200 & 57.1 \\
2,300 & 59.7 \\
2,400 & 62.2 \\
2,500 & 64.8 \\
\hline
\end{tabular}

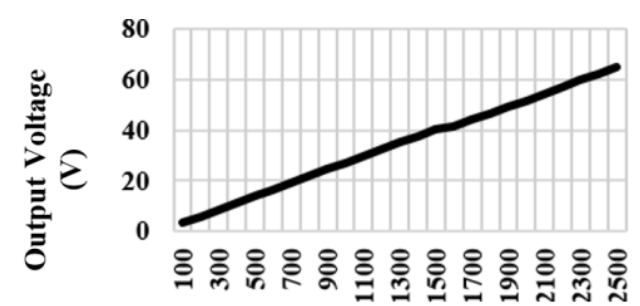

Generator Speed (rpm)

Figure 3. The relationship between rotation speed and output voltage

\subsection{Loaded-test of 3D-printed permanent magnet generator}

In the second experiment, a $7 \mathrm{~W}$ bulb is connected to the output of $3 \mathrm{D}$-printed permanent magnet generator. The first column of Table 3 and Figure 4(a) show the voltage produced when applied the load to the generator. It can be seen that when the generator is rotated at speed $100 \mathrm{rpm}$, a voltage of $2.9 \mathrm{~V}$ is generarated. When the rotation speed is increased to $2,500 \mathrm{rpm}$, a voltage of $62.8 \mathrm{~V}$ is generated. From these results it can be observed that the production of voltage slightly reduces when compared with the first experimental. Moreover, column 3 of Table 3 shows the current flow to the load, it can be seen that the increasing output current is also depend on increasing the testing speed of generator. From the experimental, it can archive a maximum output current about $67.6 \mathrm{~mA}$ at rotation speed of 2,500 rpm.

In addition, column 4 of Table 3 and Figure 4(b) shows the output power that produced from the 3D-printed permanent magnet generator. It has been shown that the output power is also depend on the rotation speed. When the rotation speed is increased to $2,500 \mathrm{rpm}$, an output power of $4,245.28 \mathrm{~mW}$ is generated. This result shows a good possibility of using 3D printer to fabricate permanent magnet generator for low power system.

The comparision of the generator fabricated by using 3D-printed materials is summarized in Table 4. It can be seen that 3D-printed can be used to make the different type of generator. In the case of permanent magnet generator, PLA material is the material that is used the most. As it can be seen from the data in Table 4, our proposed generator can generate lower power than previous work in [30], [31]. However, in this work the generator is tested with lower rotation speed. 
Table 3. The results of load test

\begin{tabular}{cccc}
\hline Speed $(\mathrm{rpm})$ & Voltage $(\mathrm{V})$ & Current $(\mathrm{mA})$ & Power $(\mathrm{mW})$ \\
\hline 100 & 2.9 & 0.4 & 1.168 \\
200 & 5.1 & 5.1 & 26.01 \\
300 & 7.7 & 7.9 & 60.83 \\
400 & 10.3 & 10.2 & 105.06 \\
500 & 12.7 & 12.9 & 163.83 \\
600 & 14.9 & 15.3 & 227.97 \\
700 & 17.6 & 18.1 & 318.56 \\
800 & 20.3 & 20.6 & 418.18 \\
900 & 22.7 & 23.3 & 528.91 \\
1,000 & 25.3 & 25.9 & 655.27 \\
1,100 & 27.7 & 28.7 & 794.99 \\
1,200 & 30.3 & 31.4 & 951.42 \\
1,300 & 32.7 & 34.1 & 1115.07 \\
1,400 & 35.1 & 36.8 & 1291.68 \\
1,500 & 37.5 & 39.5 & 1481.25 \\
1,600 & 40.2 & 43.1 & 1732.62 \\
1,700 & 42.4 & 45.9 & 1946.16 \\
1,800 & 44.9 & 48.7 & 2186.63 \\
1,900 & 47.1 & 51.6 & 2430.36 \\
2,000 & 49.7 & 54.8 & 2723.56 \\
2,100 & 52.3 & 57.5 & 3007.25 \\
2,200 & 54.2 & 60.7 & 3289.94 \\
2,300 & 57.4 & 63.3 & 3633.42 \\
2,400 & 59.7 & 66.1 & 3946.17 \\
2,500 & 62.8 & 67.6 & 4245.28 \\
\hline & & & \\
\hline
\end{tabular}

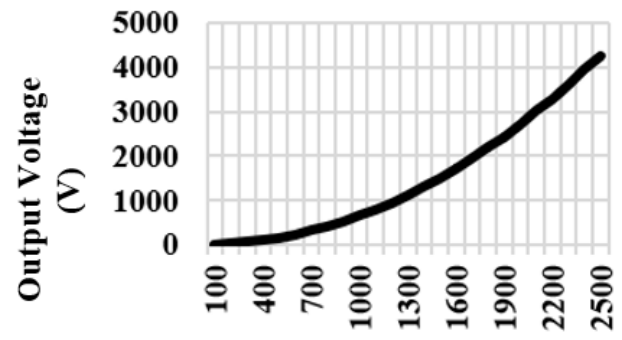

Generator Speed (rpm)

(a)

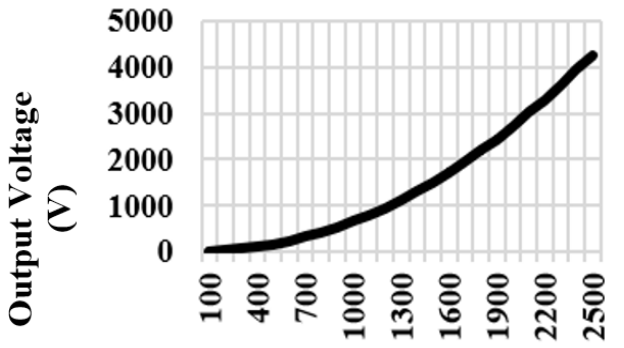

Generator Speed (rpm)

(b)

Figure 4. Output voltage and output power of proposed generator with the loaded-test: (a) the relationship between rotation speed and output voltage and (b) the relationship between rotation speed and output power

Table 4. Comparision of 3D-printed based generator

\begin{tabular}{|c|c|c|c|}
\hline Ref. & Generator type & Material & Maximum Output \\
\hline$[26]$ & Triboelectric generator & - & $3.9 \mathrm{~V}$ \\
\hline [28] & Electrostatic generators & ABS plastic & $15 \mathrm{uW}$ \\
\hline [29] & permanent magnet generator & PLA & $1,136 \mathrm{mV}$ \\
\hline$[30]$ & permanent magnet generator & PLA & 5,000 mW@6,000 rpm \\
\hline [31] & permanent magnet generator & PLA & 10,300 mV@5,000 rpm \\
\hline This work & permanent magnet generator & PLA & 4,245.28 mW@2,500 rpm \\
\hline
\end{tabular}

\section{CONCLUSION}

In this paper, we have studied a possibility to construct the permanent magnet generator using 3Dprinting technology. The experiments with prototype of 3D-printed permanent magnet generator are presented. As a result, when the rotation speed at 2,500 rpm, the proposed 3D-printed permanent magnet generator can generate maximum output voltage of 64.8 and $62.8 \mathrm{~V}$, for no-load and with load condition, respectively. Moreover, it has been found that this generator can generate the output power of 4,245.28 mW in loaded-test. This amount of output power can be used in a low-power system. The results and discussion that presented in the paper could be beneficial for future design of efficient and reliable 3D-printed permanent magnet generator for low power system. 


\section{ACKNOWLEDGEMENTS}

This research project was financially supported by Faculty of Engineering, Mahasarakham University (Fiscal.year 2019). The author also thanks Mr. Yossapat Phosophar; students of Department of Electrical Engineering who assisted in the construction of the generator presented in this paper.

\section{REFERENCES}

[1] M. U. Naseer, A. Kallaste, B. Asad, T. Vaimann, and A. Rassolkin, "A review on additive manufacturing possibilities for electrical machines," Energies, vol. 14, no. 7, pp. 1940, Mar. 2021, doi: 10.3390/en14071940.

[2] R. Wrobel and B. Mecrow, "Additive manufacturing in construction of electrical machine," in Proc. 2019 IEEE Workshop on Elec. Mach. Design, Con. and Dia. (WEMDCD), Apr. 2019, doi: 10.1109/WEMDCD.2019.8887765.

[3] K. Wang, C. Wu, Z. Qian, C. Zhang, B. Wang, and A. M. Vannan, "Dual-material 3D printed metamaterials with tunable mechanical properties for patient-specific tissue-mimicking phantoms," Add. Manu.,vol. 12, pp. 31-37, Oct. 2016, doi: 10.1016/j.addma.2016.06.006

[4] K. Wang, C. Wu, Z. Qian, C. Zhang, B. Wang, A. M. Vannan, and M. J. Wang, "Controlling the mechanical behavior of dualmaterial 3D printed meta-materials for patient-specific tissue-mimicking phantoms," Mat. and Des., vol. 90, pp. 704-712, 2016, doi: 10.1016/j.matdes.2015.11.022.

[5] M. D’Auria et al., “3-D Printed metal-pipe rectangular waveguides," IEEE Trans. on Comp., Pack. and Manu. Tech., vol. 5, no. 9, pp. 1339-1349, Sep. 2015, doi: 10.1109/TCPMT.2015.2462130.

[6] W. J. Otter et al., “3D printed $1.1 \mathrm{THz}$ waveguides,” Elec. Lett., vol. 53, no. 7, pp. 471-473, Mar. 2017, doi: 10.1049/el.2016.4662.

[7] J. Tak, D.-G. Kang, and J. Choi, "A lightweight waveguide horn antenna made via 3D printing and conductive spray coating," Micr. and Opti. Tech. Lett., vol. 59, pp. 727, Jan. 2017, doi: 10.1002/mop.30374.

[8] L. S. Araujo et al., "3-D printed band-pass combline filter," Micr. and Opti. Tech. Lett., vol. 59, p. 1388, Mar. 2017, doi: 10.1002/mop.30547.

[9] S. Jun et al., "Circular polarised antenna fabricated with low-cost 3D and inkjet printing equipment," Elec. Lett., vol. 53, no. 6, pp. 370-371, 2017, doi: 10.1049/el.2016.4605.

[10] K. So, K. Luk, C. Chan, and K. Chan, “3D Printed High Gain Complementary Dipole/Slot Antenna Array,” Appl. Sci., vol. 8, p. 1410, 2018, doi: 10.3390/app8081410.

[11] Z. Viskadourakis, K. C. Vasilopoulos, E. N. Economou, C. M. Soukoulis, and G. Kenanakis, "Electromagnetic shielding effectiveness of 3D printed polymer composites," Appl. Phys. A, vol. 123, pp. 736, Nov. 2017, doi: 10.1007/s00339-017-1353-z.

[12] S. K. Moon, Y. E. TanJihong, and H. Y. J. Yoon, "Application of 3D printing technology for designing light-weight unmanned aerial vehicle wing structures," Int. J. of Prec. Eng. and Manu. -Green Tech., vol. 1, no. 3 pp. 223-228, Apr. 2014, doi: 10.1007/s40684-014-0028-x.

[13] N. Simpson, D. J. North, S. M. Collins, and P. H. Mellor, "Additive manufacturing of shaped profile windings for minimal AC loss in electrical machines," IEEE Trans. Ind. Appl., vol. 56, no. 3, pp. 2510-2519, May 2020, doi: 10.1109/TIA.2020.2975763.

[14] N. Simpson and P. H. Mellor, "Additive manufacturing of shaped profile windings for minimal AC loss in electrical machines," in Proc. IEEE Energy Convers. Congr. Expo., pp. 5765-5772, Sep. 2018, doi: 10.1109/ECCE.2018.8557999.

[15] J. Jacimovic, F. Binda, L. G. Herrmann, F. Greuter, J. Genta, and M. Calvo, "Net shape 3D printed NdFeB permanent magnet," Adv. Eng. Mat., vol. 18, pp. 1-9, Nov. 2016, doi: 10.1002/adem.201700098.

[16] E. M. H. White, A. G. Kassen, E. Simsek, W. Tang, R. T. Ott, and I E. Anderson, "Net shape processing of alnico magnets by additive manufacturing," IEEE Trans. on Mag., vol. 53, no. 11, pp. 1-6, Nov. 2017, doi: 10.1109/TMAG.2017.2711965.

[17] T. N. Lamichhane, L. Sethuraman, A. Dalagan, H. Wang, J. Keller, and M. P. Paranthaman, "Additive manufacturing of soft magnets for electrical machines-a review," Mater. Today Phys., vol. 15, pp. 100255, Dec. 2020, doi: 10.1016/j.mtphys.2020.100255.

[18] V. Chaudhary, S. A. Mantri, R. V. Ramanujan, and R. Banerjee, "Additive manufacturing of magnetic materials," Prog. Mater. Sci., vol. 114, p. 100688, Oct. 2020, doi: 10.1016/j.pmatsci.2020.100688.

[19] M. Garibaldi, C. Gerada, I. Ashcroft, and R. Hague, "Free-form design of for production using additive manufacturing," ASME. J. Mech. Des., vol. 141, no. 7, p. 071401, July 2019, doi: 10.1115/1.4042621.

[20] S. Lammers et al., "Additive Manufacturing of a lightweight rotor for a permanent magnet synchronous machine," in Proc. 2016 $6^{\text {th }}$ Inter. Elec. Driv. Prod. Conf. (EDPC), Nov. 2016, pp. 41-45, doi: 10.1109/EDPC.2016.7851312.

[21] H. Tiismus, A. Kallaste, T. Vaimann, A. Rassõlkin, and A. Belahcen, "Additive manufacturing of prototype axial flux switched reluctance electrical machine," in Proc. $28^{\text {th }}$ Inter. Work. on Elec. Dri.: Imp. Rel. of Elec. Dri. (IWED), pp. 1-4, Jan 2021, doi: 10.1109/IWED52055.2021.9376337.

[22] A. Supardi and N. M. Dzikri, "A prototype of low power permanent magnet generator for renewable energy application," AIP Conf. Proc., vol. 2114, June 2019, doi: 10.1063/1.5112494.

[23] L. Soderlund, J.-T. Eriksson, J. Salonen, H. Vihriala, and R. Perala, "A permanent-magnet generator for wind power applications," IEEE Trans.s on Mag.,vol. 32, no. 4, pp. 2389-2392, July 1996, doi: 10.1109/20.511354.

[24] C. C. Hwang, P. H. Tang, and C. M. Chang, "Design and analysis a small permanent-magnet generator for wind power applications," Adv. Mat. Res., vol. 403, pp. 4050-4055, Nov. 2012, doi: 10.4028/www.scientific.net/amr. 403-408.4050.

[25] K. C. Latoufis, G. M. Messinis, P. C. Kotsampopoulos, and N.D. Hatziargyriou, "Axial flux permanent magnet generator design for low cost manufacturing of small wind turbines," Wind Eng., vol. 36, no. 4, pp. 411-431, 2012, doi: 10.1260/0309-524X.36.4.411.

[26] R. I. Haque, P. A. Farine, and D. Briand, "3D printed materials based triboelectric device for energy harvesting and sensing," in Proc. Euro. Conf., vol. 1, no. 4, Aug. 2017, pp. 580, doi: 10.3390/proceedings 1040580.

[27] S. Quan, L. Bu, Z. Zhou, W. Xu, B. Liang, and L. Song, "3D-printed novel triboelectric generator based on saw-toothed," in Proc. $13^{\text {th }}$ IEEE Inter. Conf. on Solid-State and Int. Cir. Tech. (ICSICT), Oct. 2016, pp. 263-265, doi: 10.1109/ICSICT.2016.7998893.

[28] A. C. M. de Queiroz and L. C. M. de Oliveira Filho, "Energy harvesting with 3D-printed electrostatic generators," IEEE $7^{\text {th }}$ Latin American Symp. on Cir. \& Sys. (LASCAS), pp. 127-130, Mar. 2016, doi: 10.1109/LASCAS.2016.7451026.

[29] C. Soemphol and N. Angkawisitittpan, "3D-printed materials based low speed permanent magnet generator for energy havesting applications," Materials Today: Proceeding, vol. 22, pp. 180-184, 2020, doi: 10.1016/j.matpr.2019.08.034. 
[30] S. G. Herawan, S. A. Syahputra, E. M. Tokit, F. Al-Z. M. Sa'at, and A. M. Rosli, "Effect of number of permanent magnetic poles on 3D printed coreless generator rotor," IOP Conf. Ser.: Mater. Sci. Eng. 1082, pp. 012009, 2021, doi: 10.1088/1757$899 \mathrm{X} / 1082 / 1 / 012009$

[31] S. G. Herawan, S. A. Syahputra, E. M. Tokit, F. Al-Z. M. Sa'at, and A. M. Rosli, "Energy harvesting application using 3D-printed coreless generator," IOP Conf. Ser.: Mater. Sci. Eng. 1082, pp. 012004, 2021, doi: 10.1088/1757-899X/1082/1/012004.

[32] S. J. Chapman, "Electric Machinery Fundamentals," McGraw-Hill, New York, pp. 4-11, 2012.

[33] E. Kurt, H. Gor, and M. Demirtas, "Theoretical and experimental analyses of a single phase permanent magnet generator (PMG) with multiple cores having axial and radial directed fluxes," Ener. Con. and Man., vol. 77, pp. 163-172, Jan. 2014, doi: 10.1016/j.enconman.2013.09.013.

\section{BIOGRAPHIES OF AUTHORS}
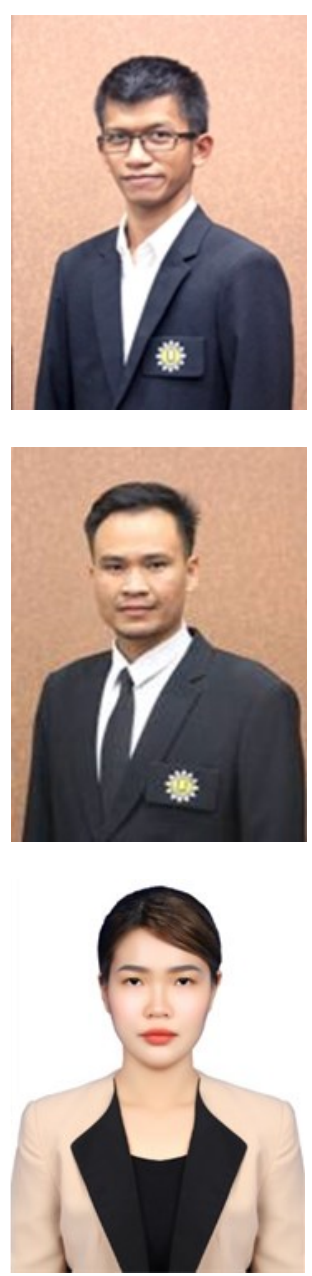

Chaiyong Soemphol (i) 81 SC $P$ was born in Surin Province, Thailand. He received his B.Eng. in Electrical Engineering with second-class honors from Khon Kaen University, Thailand in 2011. He also received his Ph.D. in Electrical Engineering from Khon Kaen University, Thailand in 2017. Since 2018, he has been with the Department of Electrical Engineering, Faculty of Engineering, Mahasarakham University, Maha Sarakham, Thailand as a Lecturer. His research interests include compact microstrip devices, metamaterial applications for RF, microwave sensor, wireless power transfer systems, reneable energy and electromechanical energy conversion. He can be contacted at email: chaiyong.s@msu.ac.th

Adisorn Nuan-on (iD 8. SC P was born in Mukdahan Province, Thailand. He received his B.Eng. in Electrical Engineering from Ubon Ratchathani University, Thailand in 2011. He received his Master of Engineering in Electrical and Computer Engineering from Mahasarakham University, Thailand in 2015. Since 2015, he has been with the Department of Electrical Engineering, Faculty of Engineering, Mahasarakham University, Maha Sarakham, Thailand as a Lecturer. His research interests include microwave sensor, RF circuits, reneable energy, automation system and electromechanical energy conversion. He can be contacted at email: adisorn.n@msu.ac.th

Peeradapath Parametpisit (iD .8. SC P was born in Maha Sarakham Province, Thailand. She received her Bachelor's Degree in Engineering (Electrical Engineering) from Mahasarakham University in 2021. Ms. Peeradapath have been spending years as a Electrical Engineer experience in farm sector of Thailand. Her research interests include System development, material development of renewable energy, solar systems and cyber physical system. She can be contacted at email: prdp.tunya@gmail.com 